Louisiana State University

LSU Digital Commons

7-1-2007

\title{
Population spread of the introduced red imported fire ant parasitoid, Pseudacteon tricuspis Borgmeier (Diptera: Phoridae), in Louisiana
}

D. C. Henne

LSU Agricultural Center

S. J. Johnson

LSU Agricultural Center

J. T. Cronin

Louisiana State University

Follow this and additional works at: https://digitalcommons.Isu.edu/biosci_pubs

\section{Recommended Citation}

Henne, D., Johnson, S., \& Cronin, J. (2007). Population spread of the introduced red imported fire ant parasitoid, Pseudacteon tricuspis Borgmeier (Diptera: Phoridae), in Louisiana. Biological Control, 42 (1), 97-104. https://doi.org/10.1016/j.biocontrol.2007.03.010

This Article is brought to you for free and open access by the Department of Biological Sciences at LSU Digital Commons. It has been accepted for inclusion in Faculty Publications by an authorized administrator of LSU Digital Commons. For more information, please contact ir@lsu.edu. 


\title{
Population spread of the introduced red imported fire ant parasitoid, Pseudacteon tricuspis Borgmeier (Diptera: Phoridae), in Louisiana
}

\author{
D.C. Henne ${ }^{\mathrm{a}, *}$, S.J. Johnson ${ }^{\text {a }}$, J.T. Cronin ${ }^{\mathrm{b}}$ \\ ${ }^{a}$ Department of Entomology, 404 Life Sciences Building, Louisiana State University Agricultural Center, Baton Rouge, LA 70803, USA \\ ${ }^{\mathrm{b}}$ Department of Biological Sciences, 202 Life Sciences Building, Louisiana State University, Baton Rouge, LA 70803, USA
}

Received 31 January 2007; accepted 26 March 2007

Available online 31 March 2007

\begin{abstract}
Predicting the spread of introduced species, such as natural enemies used in classical biological control programs, requires quantitative data on the rates of spread. Here, the pattern of spread of Pseudacteon tricuspis Borgmeier (Diptera: Phoridae), a parasitoid of the red imported fire ant (Solenopsis invicta Buren; Hymenoptera: Formicidae), was monitored at two widely separated release sites in Louisiana, USA. At both sites, P. tricuspis range expansion (measured as the mean radius of the range from four cardinal directions) was accelerating during the first four years post-release. This pattern contrasts with a linear pattern expected with simple diffusion. This suggests that population spread involved both a neighborhood diffusion and long-distance dispersal component. This is known as stratified or jump dispersal. Annual rates of spread were low in the first two years post-release (possibly owing to an Allee effect), increased rapidly in years 3-4, and slowed down or leveled off by years 5-6. Annual spread rates reached a peak of $15-25 \mathrm{~km} / \mathrm{yr}$, with the northward spread being about $40 \%$ greater than the spread in the other cardinal directions. High rates of spread in the latter years and directional bias in the spread of P. tricuspis may have been driven by prevailing winds and two northward-moving hurricanes. Spread of introduced species offers insight into factors affecting spread that is more difficult to evaluate for native species.
\end{abstract}

(c) 2007 Elsevier Inc. All rights reserved.

Keywords: Biological control; Long-distance dispersal; Range expansion; Spatial spread; Stratified dispersal

\section{Introduction}

Classical biological control involving the introduction of natural enemies to suppress exotic pest species has been ongoing for more than a century (see Huffaker and Messenger, 1976; Coulson et al., 2000). Success of the biological control agent depends in part on its ability to establish, spread and eventually occupy the range of its host. For example, successful biological control of the chestnut gall wasp, Dryocosmus kuriphilus Yasumatsu (Hymenoptera: Cynipidae), in Japan was achieved by the introduction and rapid spread (approximately $60 \mathrm{~km} / \mathrm{yr}$ ) of the introduced parasitoid, Torymus sinensis Kamijo (Hymenoptera: Torymidae) (Moriya et al., 2002). Early models of the spread of animal and plant populations were based on

\footnotetext{
* Corresponding author. Fax: +1 2255781643.

E-mail address: DHenne@agcenter.lsu.edu (D.C. Henne).
}

the process of diffusion and predicted a simple linear rate of spread (Fisher, 1937; Skellam, 1951; reviewed by Hengeveld, 1989; Andow et al., 1990; Okubo and Levin, 2002; Hastings et al., 2005). However, empirical patterns of spread for many species are nonlinear, likely attributable to appreciable rates of long-distance dispersal (e.g., Hengeveld, 1989; Andow et al., 1993; Shigesada et al., 1995; Johnson et al., 2006; Muirhead et al., 2006). In these species, nascent populations appear well beyond the edge of an expanding range in what is known as stratified or "jump" dispersal (Hengeveld, 1989).

For many species, human transport processes, such as the movement of the Argentine ant (Linepithema humile (Mayr) by cars and trucks (Suarez et al., 2001), or the zebra mussel (Dreissena polymorpha (Pallas)) by boats (Buchan and Padilla, 1999) are thought responsible for jump dispersal. Ignoring this component of dispersal can lead to significant underestimates of range expansion of invasive 
pests and natural enemies introduced for their biological control.

The red imported fire ant, Solenopsis invicta Buren (Hymenoptera: Formicidae), is a ubiquitous and economically important pest in the southeastern United States (Lofgren, 1986). Much has been published about the introduction, spread, biology, economic and environmental impacts, and control of $S$. invicta in the United States (see Vinson, 1997; Tschinkel, 2006). Early efforts to eradicate $S$. invicta with chemical control were met with limited success (Taber, 2000; Tschinkel, 2006). Recently, more attention has focused on the potential for biological control of $S$. invicta by importing several specialist parasitoids in the genus Pseudacteon Coquillet (Diptera: Phoridae) from the indigenous range of $S$. invicta in South America.

Pseudacteon tricuspis Borgmeier was the first phorid fly species introduced to the United States for biological control of S. invicta. It was initially released in Texas in 1995 (Gilbert, 1996) and Florida in 1997 (Porter et al., 1999). In cooperation with the USDA-ARS, the first releases of P. tricuspis in Louisiana took place in September 1999 and May 2000. Pseudacteon tricuspis successfully established at each release site (Henne and Johnson, unpublished data).

Available information on dispersal and spread of Pseudacteon flies is limited to three studies. Using traps baited with $S$. geminata (Fabricius) workers, Morrison et al. (1999a) found that Pseudacteon parasitoids in Texas dispersed up to $650 \mathrm{~m}$ from the nearest $S$. geminata population. Porter et al. (2004) monitored the spread of $P$. tricuspis from multiple release sites in north-central Florida and found that the average rate of spread was $10-30 \mathrm{~km} / \mathrm{yr}$. With an additional two years of data, Pereira and Porter (2006) revised these latter estimates to $26-57 \mathrm{~km} / \mathrm{yr}$. These studies did not evaluate whether Pseudacteon spread fit the theoretical expectations of neighborhood diffusion or that of stratified dispersal (see Shigesada et al., 1995; Hastings et al., 2005). Data of this sort are useful in understanding animal movement behavior and is necessary to develop predictive models of species spread (Turchin, 1998). The aim of this paper is to describe and model the spread of two established P. tricuspis populations in Louisiana.

\section{Materials and methods}

\subsection{Biology of Pseudacteon parasitoids}

Parasitic flies of the genus Pseudacteon contribute to maintaining lower abundances of S. invicta in South America (Porter et al., 1992), and thus may be useful in the suppression of $S$. invicta populations in the United States. Although there are native species of Pseudacteon that attack native North American fire ants ( $S$. geminata and $S$. xyloni McCook), they have never been observed to attack $S$. invicta. By reuniting $S$. invicta with several species of its native Pseudacteon parasitoids, it is hoped that the ant communities in the United States that are currently dominated by $S$. invicta may shift in favor of native ant species (Porter, 1998).

Phorid parasitoids locate their hosts by detecting ant semiochemicals (Porter, 1998; Morrison and King, 2004). For example, $P$. tricuspis is attracted to alarm pheromones emitted by $S$. invicta during mound disturbances, alate flights, and intra- and interspecific fighting (Williams et al., 1973; Pesquero et al., 1993; Morrison and King, 2004), and primarily attacks major workers (Morrison et al., 1999b). Female Pseudacteon inject a single egg into the host ants' thorax, the larva consumes the head contents and eventually pupariates inside the empty decapitated head capsule (Porter et al., 1995).

A considerable body of evidence suggests that parasitic phorid flies mediate competitive interactions between various ant species (e.g., Feener, 1981; Feener and Brown, 1992; Folgarait and Gilbert, 1999; Morrison, 1999, 2000; Orr et al., 1995, 2003). Solenopsis spp. workers will reduce or terminate foraging activity in response to attacks by Pseudacteon flies (Feener and Brown, 1992; Orr et al., 1995; Morrison, 1999). Mehdiabadi and Gilbert (2002) found that a single attacking $P$. tricuspis female per 200 foraging $S$. invicta workers decreased colony protein consumption almost twofold and significantly reduced numbers of large-sized workers 50 days later. These studies demonstrate the potential for Pseudacteon parasitoids to reduce $S$. invicta populations (but see Tschinkel, 2006).

\subsection{Release sites}

Initial $P$. tricuspis releases in Louisiana were conducted at the following locations: (1) $17 \mathrm{~km}$ northeast of Coving-

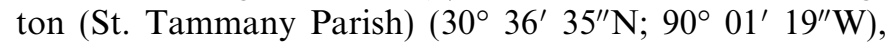
8-13 September 1999 (2165 flies released); (2) $9 \mathrm{~km}$ east of Norwood (East Feliciana Parish) $\left(30^{\circ} 59^{\prime} 05^{\prime \prime} \mathrm{N}\right.$; $91^{\circ} 00^{\prime} 46^{\prime \prime} \mathrm{W}$ ), 27 April-8 May 2000 (4714 flies released). These release sites were unmaintained pastures located approximately $100 \mathrm{~km}$ apart and had abundant $S$. invicta populations. Adult $P$. tricuspis were released at disturbed S. invicta mounds over a 6-12 day period, and approximately 400 flies were released daily at ten disturbed $S$. invicta mounds. Mounds were continuously disturbed for $2 \mathrm{~h}$ to maintain $S$. invicta activity and availability to oviposition by P. tricuspis (Porter et al., 2004).

\subsection{Evaluating population expansion}

Post-release surveys to determine the annual spread limits of $P$. tricuspis were conducted during the fall of each year (September to November) when abundances were highest (Henne and Johnson, unpublished data). Fly surveys were normally conducted between 1100 and $1700 \mathrm{~h}$ when ambient temperatures were warm enough for fly activity $\left(>20^{\circ} \mathrm{C}\right)$ (Morrison et al., 1999a). We monitored the spread of $P$. tricuspis along transects in four cardinal directions (i.e., north, south, east, and west) from the release point. Every year, we started our survey along each 
transect, approximately $3 \mathrm{~km}$ outward from the previous year's range limit. Within a $100 \mathrm{~m}$ radius of that point, we located $10 \mathrm{~S}$. invicta mounds in disturbed habitat (e.g., roadsides, pastures). Two of us (D.H. and S.J.) would vigorously disturb the mounds with spades (5-10 s) and count the number of $P$. tricuspis adults that arrived during the ensuing of $30 \mathrm{~min}$. Normally, flies would appear within a few minutes of mound disturbance. The sampling location was also recorded with a Magellan ${ }^{\text {TM }}$ GPS 315/320 (accurate to within $25 \mathrm{~m}$ ) for later plotting on a computer mapping program $\left(\right.$ Maptech $^{\circledR}$ Terrain Navigator Pro) or Google ${ }^{\mathrm{TM}}$ Earth.

If no flies were detected at the disturbed mounds within $30 \mathrm{~min}$, we moved approximately $1 \mathrm{~km}$ (the exact distance depended on the presence of suitable $S$. invicta habitat) toward the release area. If flies were present, the researchers moved 1-2 km further away from the release area. The survey was continued in each direction until the limits of spread were established to within $1 \mathrm{~km}$ of their approximate locations. Annual surveys were conducted from 1999 (approx. 40 days post-release) to 2005 for the Covington release and from 2001-2006 for the Norwood release (approx. one year post-release).

\subsection{Modeling $P$. tricuspis range expansion}

\subsubsection{Average radius of spread}

The mean radius from a point of introduction is the simplest measure of a species' range and provides an estimate of the expansion rate when it is obtained at known time intervals (Hengeveld, 1989). The change in spread radius with time is expected to take on one of three forms: linear (constant rate of spread as predicted by early diffusionbased models), accelerating (rate of spread continually increases over time), or biphasic (initially slow rate of expansion followed by an abrupt transition to an accelerating expansion rate) (Shigesada et al., 1995; Turchin, 1998). The mean $\pm \mathrm{SE}$ annual spread radius (based on four transects) for each expanding $P$. tricuspis population in Louisiana was computed. Linear (null model) and quadratic polynomials were fitted to the mean annual spread radius of both populations and compared using the extra sumof-squares $F$-test in Prism ${ }^{\circledR} 4.03$ (GraphPad Software, Inc., San Diego, CA). The linear and quadratic terms were deemed significant if the associated $p$-values were $\leqslant 0.05$.

\subsubsection{Annual spread rates}

Simple models of diffusion predict the spread rate of $P$. tricuspis to be constant over time (Shigesada et al., 1995; Turchin, 1998). If this is not the case, we can identify time periods for which the rate of spread is low (e.g., if an Allee effect is operating during the early stages of range expansion), or accelerating. Because both populations exhibited consistent directional bias in expansion rates (see Section 3 ), separate curves were generated for each transect. To more clearly depict the latent, accelerating and plateau phases of expansion over time, we plotted the relationship between annual spread rate (spread radius in year $t$ minus the spread radius in year $t-1$ ) and year since release. A logistic model was fit to the Covington 2000-2005 north and west annual spread rates, and to the 2000-2004 south and east spread rates using Prism ${ }^{\circledR} 4.03$. Because the Norwood population did not exhibit any measurable spread in the first two years (zero individuals in 2001 and two individuals among 74 mounds in 2002), there were too few data points to fit the logistic model to its annual spread rates. The logistic model used was a dose-response model, equivalent to a three-parameter logistic model (Motulsky and Christopoulos, 2003) and had the analytic form: $y=$ Bottom $+\left[(\right.$ Top - Bottom $\left.) / 1+10^{\operatorname{LogEC}} 50-x\right]$. The parameters, bottom (constrained $>0$ ) is the $y$-value at the bottom plateau, top is the $y$-value at the top plateau, and $\operatorname{LogEC}_{50}$ is the $x$-value halfway between bottom and top.

\subsubsection{Decline of $P$. tricuspis abundances away from release points}

One expectation of simple spatial spread models is that the density of the organism should decay at an approximately exponential rate with distance from the release point (Turchin, 1998; Okubo and Levin, 2002). When abundances are 1 -transformed, the relationship is expected to be linear. Data from $P$. tricuspis transect surveys were transformed $[\ln (n+1)]$, where $n$ is the total number of flies observed at $10 \mathrm{~S}$. invicta mounds. Linear regression was performed using Prism ${ }^{\circledR} 4.03$.

\section{Results}

\subsection{Pseudacteon tricuspis range expansion}

Both the Covington and Norwood P. tricuspis releases resulted in expanding populations (Table 1). By the fall of 2005, the leading edges of the westward expanding Covington and eastward expanding Norwood populations were approximately $8 \mathrm{~km}$ apart. Based on expansion rates at that time (see below), these populations were projected to merge in 2006. Thus, the Covington survey was terminated after the 2005 survey. The Norwood population was surveyed through 2006, but the presumed merger prevented us from determining its eastern expansion limit.

For both populations, the average annual radius of spread increased nonlinearly with year since release (Fig. 1). Adding a quadratic term to the linear models significantly improved the fit [Covington $d f=1,3$ $(F=164, \quad p=0.001) \quad y=3 x^{2}-12000 x+1.2 \mathrm{e}^{0.007}$ $\left(R^{2}=1.0, n=6\right)$; Norwood $d f=1,3(F=85, p=0.003)$, $\left.y=4.2 x^{2}-17000 x+1.7 \mathrm{e}^{0.007}\left(R^{2}=0.99, n=6\right)\right]$. In both populations, range expansion was biased to the north of each release site (Table 1). In Covington, northward expansion as of 2004 was $10.5 \mathrm{~km}$ ( or $41 \%$ ) farther than the mean expansion for the other three directions. In Norwood, the difference as of 2006 was $23.5 \mathrm{~km}$ (or $40 \%$ ).

The rate of spread of $P$. tricuspis varied tremendously among years between the Covington and Norwood releases 
Table 1

Pseudacteon tricuspis cumulative spread radius $(\mathrm{km})$, annual spread distance (radius at year $t$ minus radius at $t-1$; in parentheses), and estimated area occupied $\left(\mathrm{km}^{2}\right)$ for different transects and years at the Covington and Norwood releases

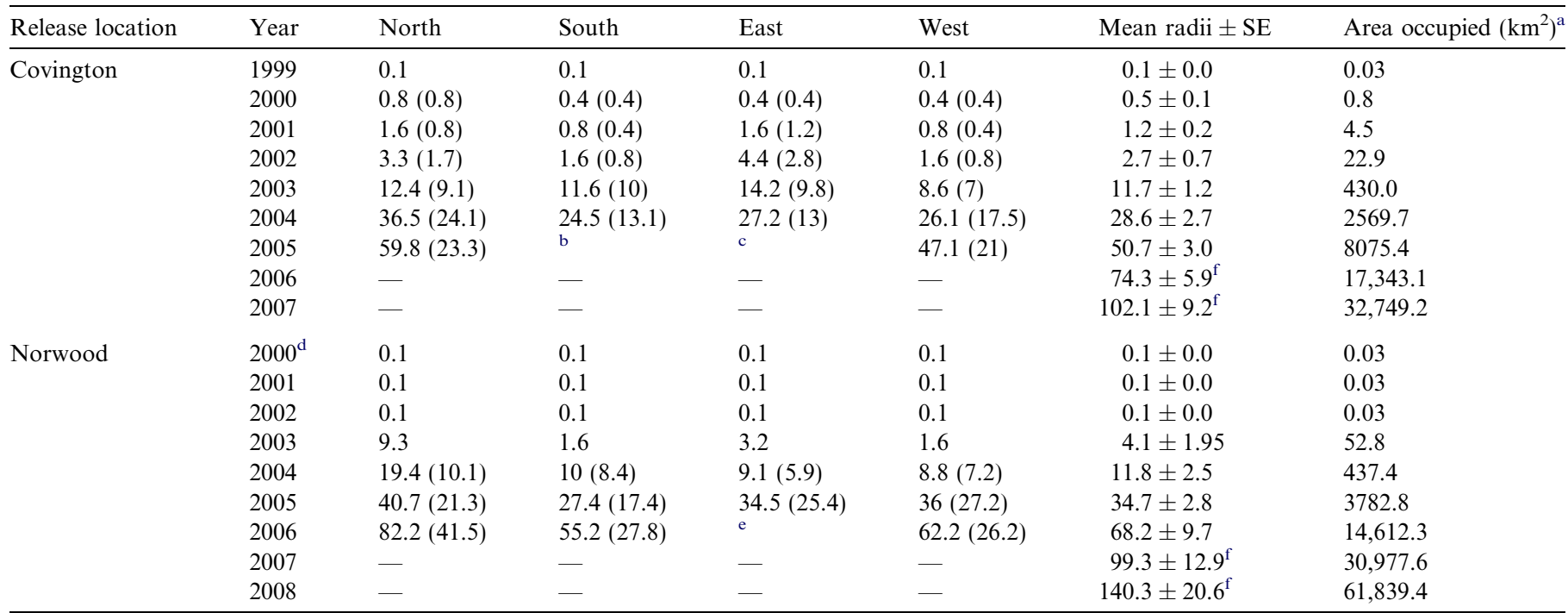

a Based on the area of a circle $\left(\pi r^{2}\right)$.

${ }^{b}$ Southward expansion reached Lake Pontchartrain in 2004.

${ }^{\mathrm{c}}$ Eastward expansion merged with Mississippi P. tricuspis in 2005.

d 2000-2002 Norwood radii based on 1999 Covington radii.

e Eastward expansion merged with Covington P. tricuspis in 2006.

${ }^{\mathrm{f}}$ Predicted radii computed from quadratic models (see text).
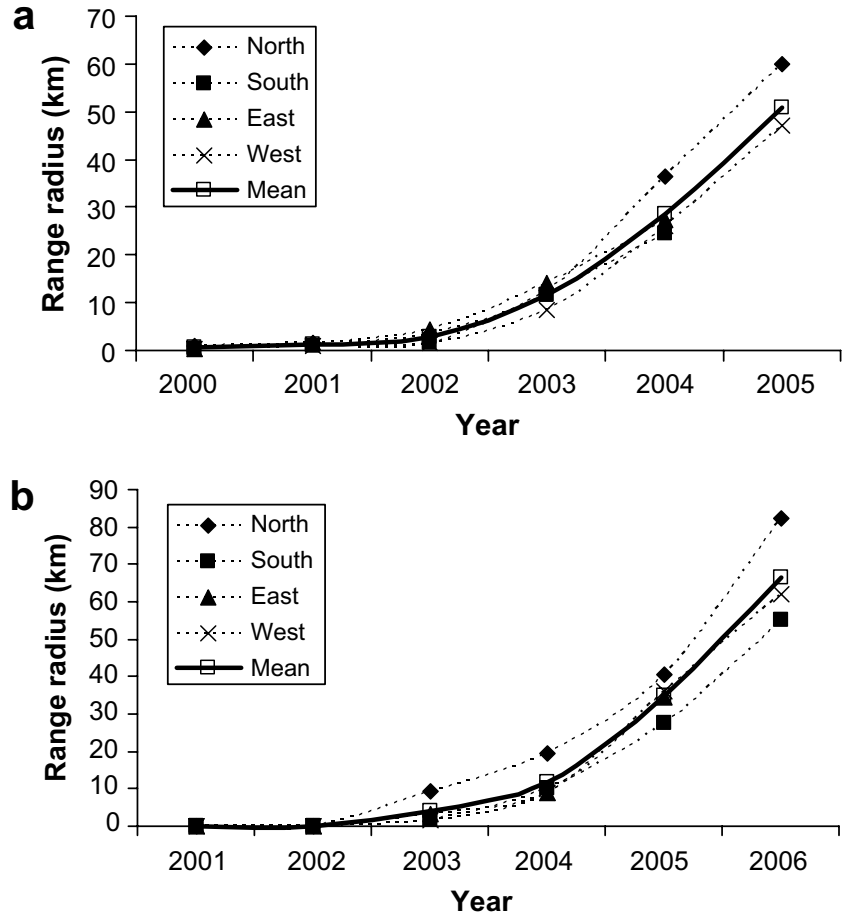

Fig. 1. (a) The change in Pseudacteon tricuspis range radius $(\mathrm{km})$ over time in four cardinal directions (and mean of all directions) for two release sites: Covington (a) and Norwood (b), Louisiana. Curves are derived from polynomial least-squares regression (see Section 3).

(Fig. 2). The annual rate of spread at the Covington site was sigmoidal over time - the spread rate was very low
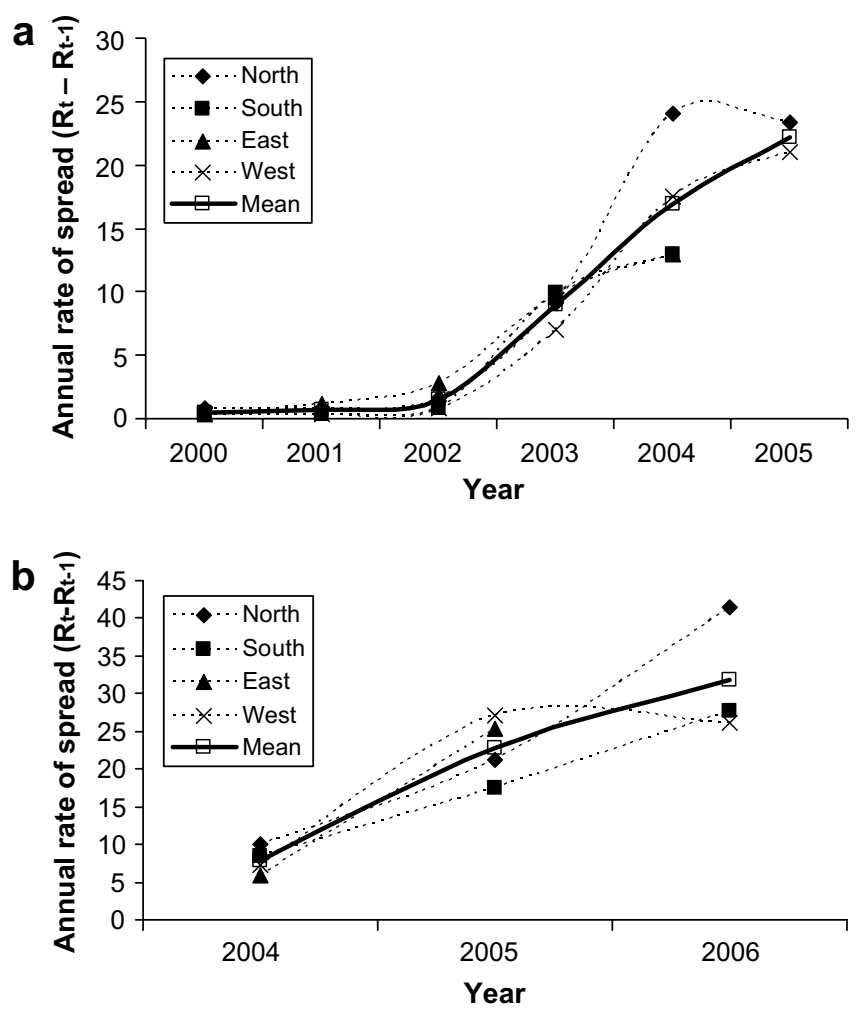

Fig. 2. Annual directional rate of spread $\left(\mathrm{km} / \mathrm{year}=\right.$ radius at time ${ }_{t}-$ radius at time ${ }_{t-1}$ ) for P. tricuspis at the Covington (a) and Norwood (b) release sites. A logistic growth curve (see Section 2) is fit to each individual transect and the mean of all four transects. 
in the first two years following the release, then it increased rapidly during years $3-4$, and finally appeared to slow down or level off at a mean maximal rate of spread of $23 \mathrm{~km} / \mathrm{yr}$ (Table 1 and Fig. 2a). Although, we do not have sufficient data from the Norwood release (Table 1 and Fig. 2b) to compare range expansion in the first couple of years to that from subsequent years, we do observe a steady increase in the rate of spread from years 3-5. The rates of spread during this time period are very comparable to those for the Covington release, differing only by an average of $2.6 \mathrm{~km}$ (or $15 \%$ ). A paired $t$-test (using Prism ${ }^{\circledR}$ 4.03) comparing years 3-5 spread rates between both populations was nonsignificant $[d f=2, t=1.39, p=0.3]$.

The logistic models provided a very good fit to the latent, accelerating and plateau phases of the Covington spread rate data: north $y=0.4528+[(25.25-0.4528) /$ $\left.1+10^{\log 4.199-x}\right] \quad\left(R^{2}=0.99\right), \quad$ south $\quad y=1.0$ $\mathrm{e}^{-0.007}+\left[\left(14.2-1.0 \mathrm{e}^{-0.007}\right) / 1+10^{\log 3.740-x}\right] \quad\left(R^{2}=0.98\right)$, east $y=0.5659+\left[(13.6-0.5659) / 1+10^{\log 3.636-x}\right]\left(R^{2}=0.99\right)$, west $\quad y=0.2096+\left[(21.43-0.2096) / 1+10^{\log 4.336-x}\right]$ $\left(R^{2}=0.99\right)$. Covington asymptotic spread rates are projected by the logistic models to be approximately 25 $\mathrm{km} / \mathrm{yr}$ (north), $14 \mathrm{~km} / \mathrm{yr}$ (south and east), and $21 \mathrm{~km} / \mathrm{yr}$ year (west). The Norwood western spread distance in 2006 was similar to the 2005 spread distance ( $26 \mathrm{~km}$ vs. $27 \mathrm{~km}$ ).

\subsection{Decline of P. tricuspis abundances away from release points}

For both point-in-time surveys of the abundances of P. tricuspis at the edge of the Norwood range, we found that In fly abundances declined linearly with increasing distance from the release point, $[2005$ east transect $d f=1,3$ $(F=133.5)\left(R^{2}=0.98, n=5\right) p<0.01 ; 2006$ south transect $d f=1,3(F=37.59)\left(R^{2}=0.93, n=5\right) p<0.01$; Fig. 3].

\section{Discussion}

Range expansion by $P$. tricuspis was not linear as predicted by classical models of diffusive spread. Instead, the rate of spread accelerated during the first five years post-release and appeared to slow down or level off in subsequent years (at least for the Covington site). For both Covington and Norwood, populations were spreading at a rate of approximately $15-25 \mathrm{~km} / \mathrm{yr}$ by the end of the study. The accelerating phase of range expansion is similar to the type 3, bi-phasic curve described by Shigesada et al. (1995). It is also suggestive of stratified dispersal in P. tricuspis.

Rapid expansion rates, such as those observed in the third through fourth years following the release of $P$. tricuspis in Covington and Norwood, can occur when a few mated female parasitoids disperse very far in relation to the typical neighborhood movements of most individuals (Hastings, 2000). Jump dispersal can result from intrinsic dispersal heterogeneities within a population, owing to differences in body size, wing morphology and movement
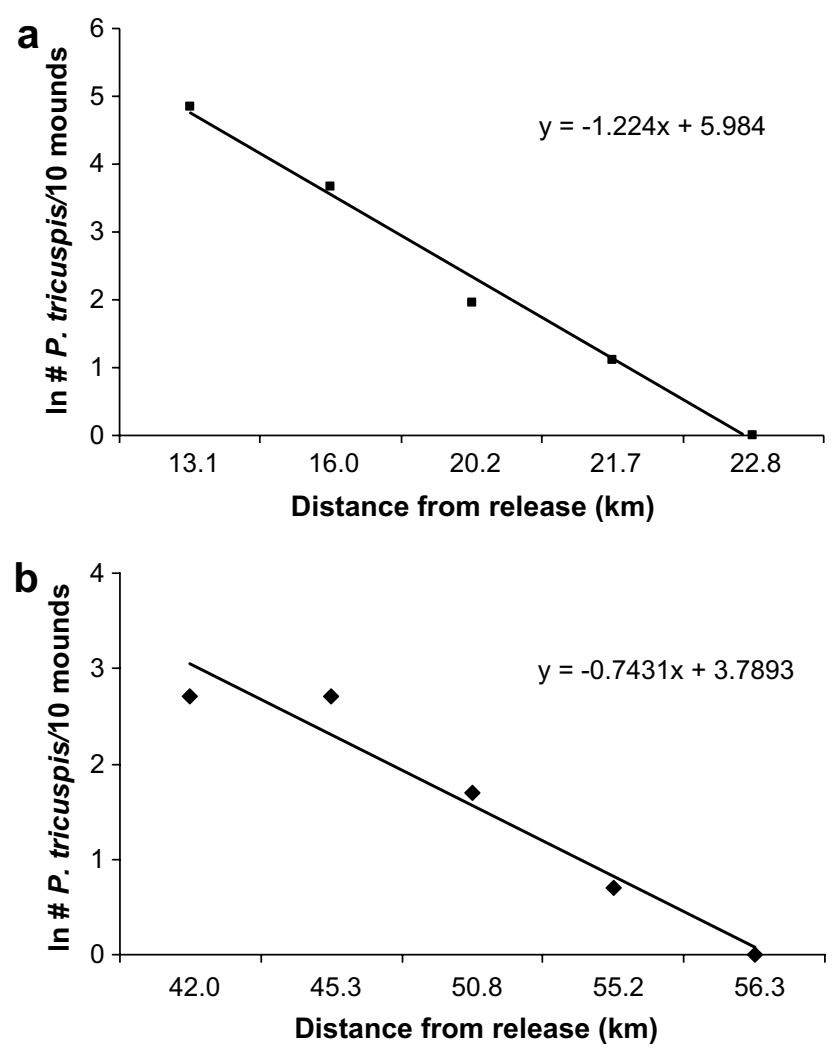

Fig. 3. In number of $P$. tricuspis/10 mounds at different distances from the release point at Norwood. (a) East transect, 10 October 2005, (b) South transect, 11 October 2006.

behavior (Cronin et al., 2000; Yamamura, 2002). It can also result from human-assisted transport of a small subset of the population (e.g., Buchan and Padilla, 1999; Suarez et al., 2001). Presently, we do not have any information on whether $P$. tricuspis exhibits intrinsic differences in dispersal ability or if humans might assist in their spread.

At low initial population densities, the few long-distance dispersers would have little impact on the velocity of the advancing neighborhood diffusion wave (Hengeveld, 1989). However, as densities increase, the number of long-distance dispersers will increase and may become a dominant component of the advancing wave (Hengeveld, 1989). Eventually, even with stratified dispersal, spread rates should reach an asymptote as densities equilibrate; after which time the mean radius of spread (or square root of area occupied) versus time function would become linear (see Hengeveld, 1989; Moriya et al., 2002; Yamamura, 2002).

Many organisms introduced to a new environment undergo an initial period of little or no expansion, called a 'latent phase' (Turchin, 1998). This is an important first step in the eventual establishment and spread of introduced organisms. It is a time when the population presumably adapts to local conditions and increases its numbers (Turchin, 1998; Andow, 1999). This latent phase may be caused by an Allee effect, whereby introduced insects dispersing into a new environment may become so rare that 
males and females often fail to encounter one another (Hopper and Roush, 1993). In their review of the literature, Hopper and Roush (1993) found that establishment success of introduced parasitoids depended on the release density and number of releases. This suggests that Allee effects may represent an important constraint on the success of biological control programs using parasitoids.

Introduced organisms may also have an 'eclipse' period in which abundances shortly after the release fall below a detection threshold, (Hopper and Roush, 1993). This can occur in situations when dispersal rates are high, thereby acting as a 'drain' on local populations at the release site (Kean and Barlow, 2000). Despite high P. tricuspis abundances ( $>5$ flies/mound) at the Norwood release site during 2000 , flies were not detected at the release site one year later, and only two flies were observed the second year after introduction, despite intensive sampling. By the third year post-release, $P$. tricuspis had already spread up to $10 \mathrm{~km}$ away from the release area. A combination of slowerthan-expected local increase at the release site (i.e., during the eclipse period), followed by rapidly increasing rates of spread beginning in the third year (Fig. 2), may have been responsible for the sudden appearance of $P$. tricuspis so far from the release site (Kean and Barlow, 2000). Clearly, the negligible population abundances at the Norwood release site 1-2 years post-release were not a reliable indication of the true status of this population. In future releases, more intensive and wider-ranging surveys should be conducted initially when population densities are low.

Porter et al. (2004) documented P. tricuspis expansion rates that were comparable to the rates we found in the Louisiana releases - $10-30 \mathrm{~km} / \mathrm{yr}$ in central Florida versus $15-25 \mathrm{~km} / \mathrm{yr}$ in Louisiana. The Florida releases also appeared to exhibit accelerating spread rates, although Porter et al. (2004) did not attempt to quantify this pattern. Expansion rates in Florida appeared to have accelerated more quickly than in Louisiana, reaching approximately $23 \mathrm{~km} / \mathrm{yr}$ only three years post-release. Porter et al. (2004) also found that $P$. tricuspis abundances decreased with increasing distances away from release points, and Morrison et al. (1999a) documented declining abundances of Pseudacteon parasitoids of $S$. geminata at increasing distances from host colonies in Texas. A species' population density tends to be highest near the center and gradually declines towards the margin of its geographical range (Guo et al., 2005). This can be attributed to an area-dilution effect (Turchin, 1998). As distance from the release point increases, the numbers of organisms reaching that distance are spread over a progressively larger area. The log-linear declines of $P$. tricuspis abundances with increasing distance away from the source population suggest a probability distribution function (kernel) with a long tail of $P$. tricuspis dispersers (i.e., exponential decline in abundance). Similar declines in abundances along other transects near the range edges were observed in both Louisiana populations (Henne and Johnson, unpublished data).
Another similarity between our Louisiana releases and the Florida releases (Pereira and Porter, 2006) is that there is a northward bias in P. tricuspis spread. Areas near coastal Louisiana are subjected to afternoon sea breezes that blow north from the Gulf of Mexico and occur almost daily during the warm season (Smith and Fuelberg, 2005). Morrison et al. (1999a) suggested that most Pseudacteon remain close to the ground during high winds, but also that passive transport by wind may be an important factor in long-distance dispersal. In support of this claim, P. tricuspis have successfully dispersed across the Mississippi river $(>1 \mathrm{~km})$ and beyond dense forest stands (e.g., Bogue Chitto National Wildlife Refuge) that were at least $5 \mathrm{~km}$ wide and at least $20 \mathrm{~km}$ deep (as measured in Google ${ }^{\mathrm{TM}}$ Earth).

Microinsects routinely form concentrated well-defined plumes in thermal currents of rising air (Geerts and Miao, 2005) suggesting that long-distance dispersal via winds may be important in the spatial spread of these species. The detection of $P$. tricuspis nearly $42 \mathrm{~km}$ further north of the Norwood release site in the 2006 as compared to the 2005 survey was considerably farther than any previous recorded spread distance for this species, including the Florida releases reported in Porter et al. (2004). An explanation for this may have been the influence of two hurricanes (Katrina and Rita) that made landfall in Louisiana in 2005. High winds associated with these large-scale synoptic events as they approached and moved northward through Louisiana (http://www.nhc.noaa.gov/ 2005atlan.shtml) would have transported dispersing $P$. tricuspis adults farther away than normal. In Florida, four hurricanes with a generally northward trajectory in 2004 (Charley, Frances, Ivan, and Jeanne) (http:// www.nhc.noaa.gov/2004atlan.shtml) may explain the enhanced $P$. tricuspis spread rates reported by Pereira and Porter (2006) in Florida. Several studies have shown that tropical cyclones account for long-distance transport of many insects (e.g., Larsen and Pedgley, 1985; Torres, 1988; Richardson and Nemeth, 1991; Clarke and Zalucki, 2004). Thus, model-based predictions of future expansion distances may be prone to considerable directional bias. Regardless of how directional bias occurs, $P$. tricuspis populations do spread considerable distances on an annual basis, a feature that will contribute to its ability to quickly occupy the range of $S$. invicta (see also Porter et al., 2004; Pereira and Porter, 2006).

Nearly 20 species of Pseudacteon are known to attack $S$. invicta in South America (Porter and Pesquero, 2001), and at least three species of Pseudacteon have already been imported and released in the United States: P. tricuspis (Graham et al., 2001; Porter et al., 2004), P. curvatus Borgmeier (Graham et al., 2003), and P. litoralis Borgmeier (Porter and Alonso, 1999). Pseudacteon borgmeieri Schmitz (Folgarait et al., 2002a) and P. cultellatus Borgmeier (Folgarait et al., 2002b) are currently under evaluation for possible release in the United States in the next few years. This study provides valuable information about $P$. tricuspis population spread that can be used in predicting spread 
rates and distances (with directional bias) for this and other Pseudacteon species. The fact that $P$. tricuspis spread patterns and rates are so similar in Louisiana and Florida suggests that our predictions would be robust for releases of this species throughout the southeastern United States.

\section{Acknowledgments}

The authors acknowledge the following individuals for permitting release of $P$. tricuspis on their properties: $\mathrm{Mr}$. Gant Boswell (Covington) and Dr. Jack Jones (Norwood). Dr. Sanford Porter (USDA-ARS) assisted with the Covington release and provided $P$. tricuspis for the releases described in this paper. Thanks are extended to Gregg Henderson and Tim Schowalter for helpful comments and criticisms of this manuscript. Published with the approval of the Director of the Louisiana Agricultural Experiment Station as Manuscript number 07-26-0080. J.T. Cronin was supported by National Science Foundation Grant DEB-0515764.

\section{References}

Andow, D.A., Kareiva, P.M., Levin, S.A., Okubo, A., 1990. Spread of invading organisms. Landscape Ecol. 4, 177-188.

Andow, D.A., Kareiva, P.M., Levin, S.A., Okubo, A., 1993. Spread of invading organisms: patterns of spread. In: Kim, K.C., McPheron, B.A. (Eds.), Evolution of Insect Pests: Patterns of Variation. John Wiley and Sons, New York, pp. 219-242.

Andow, D.A., 1999. Spread of invading organisms. In: Biological Invasions of Ecosystem by Pests and Beneficial Organisms. In: Yano, E., et al. (Eds.), NIAES Series, No. 3. Tsukuba, Japan, pp. 66-77.

Buchan, L.A.J., Padilla, D.K., 1999. Estimating the probability of longdistance overland dispersal of invading aquatic species. Ecol. Appl. 9, 254-265.

Clarke, A.R., Zalucki, M.P., 2004. Monarchs in Australia: on the winds of a storm? Biol. Invas. 6, 123-127.

Coulson, J.R., Vail, P.V., Dix, M.E., Nordlund, D.A., Kauffman, W.C. (Eds.), 2000. 110 years of Biological Control Research and Development in the United States Department of Agriculture: 1883-1893. Agricultural Research Service, U.S. Department of Agriculture, Washington, DC.

Cronin, J.T., Reeve, J.D., Wilkens, R., Turchin, P., 2000. The pattern and range of movement of a checkered beetle predator relative to its bark beetle prey. Oikos 90, 127-138.

Feener Jr., D.H., 1981. Competition between ant species: outcome controlled by parasitic flies. Science 214, 815-817.

Feener Jr., D.H., Brown, B.V., 1992. Reduced foraging of Solenopsis geminata (Hymenoptera: Formicidae) in the presence of parasitic Pseudacteon spp. (Diptera: Phoridae). Ann. Ent. Soc. Am. 85, 80-84.

Fisher, R.A., 1937. The wave of advance of advantageous genes. Ann. Eugenic. 7, 355-369.

Folgarait, P.J., Gilbert, L.E., 1999. Phorid parasitoids affect foraging activity of Solenopsis richteri under different availability of food in Argentina. Ecol. Entomol. 24, 163-173.

Folgarait, P.J., Bruzzone, O.A., Patrock, R.J.W., Gilbert, L.E., 2002a. Developmental rates and host specificity for Pseudacteon parasitoids (Diptera: Phoridae) of fire ants (Hymenoptera: Formicidae) in Argentina. J. Econ. Ent. 95, 1151-1158.

Folgarait, P.J., Bruzzone, O.A., Gilbert, L.E., 2002b. Development of Pseudacteon cultellatus (Diptera: Phoridae) on Solenopsis invicta and Solenopsis richteri fire ants (Hymenoptera: Formicidae). Environ. Ent. 31, 403-410.
Geerts, B., Miao, Q., 2005. A simple numerical model of the flight behavior of small insects in the atmospheric convective boundary layer. Environ. Ent. 34, 353-360.

Gilbert, L.E., 1996. Prospects of controlling fire ants with parasitoid flies: the perspective from research based at Brackenridge Field Laboratory. In: Cohen, W.E. (Ed.), Texas Quail Short Course II. Texas Agricultural Extension Service, Texas A\&M UniversityKingsville, pp. 77-92.

Graham, L.C., Porter, S.D., Flanders, K.L., Kelley, A.T., Dorough, H.D., Hudson, R.G., 2001. Introduction of phorid flies for the biological control of fire ants in Alabama. In: Proceedings of the 2001 Imported Fire Ant Conference, San Antonio, TX, pp. 151-152.

Graham, L.C., Porter, S.D., Pereira, R.M., Dorough, H.D., Kelley, A.T., 2003. Field releases of the decapitating fly Pseudacteon curvatus (Diptera: Phoridae) for control of imported fire ants (Hymenoptera: Formicidae) in Alabama, Florida, and Tennessee. Fla. Entomol. 86, 334-339.

Guo, Q., Taper, M., Schoenberger, M., Brandle, J., 2005. Spatialtemporal population dynamics across species range: from centre to margin. Oikos 108, 47-57.

Hastings, A., 2000. Parasitoid spread: lessons for and from invasion biology, pp. 70-82. In: Hochberg, M.E., Ives, A.R. (Eds.), Parasitoid Population Biology. Princeton University Press, Princeton, New Jersey, xiv +366 pp.

Hastings, A., Cuddington, K., Davies, K.F., Dugaw, C.J., Elmendorf, S., Freestone, A., Harrison, S., Holland, M., Lambrinos, J., Malvadkar, U., et al., 2005. The spatial spread of invasions: new developments in theory and evidence. Ecol. Lett. 8, 91-101.

Hengeveld, R., 1989. Dynamics of Biological Invasions. Chapman and Hall, London.

Hopper, K.R., Roush, R.T., 1993. Mate finding, dispersal, number released, and the success of biological control introductions. Ecol. Entomol. 18, 321-331.

Huffaker, C.B., Messenger, P.S. (Eds.), 1976. Theory and Practice of Biological Control. Academic Press, New York.

Johnson, D.M., Liebhold, A.M., Tobin, P.C., Bjørnstad, O.N., 2006. Allee effects and pulsed invasion by the gypsy moth. Nature 444, 361363.

Kean, J.M., Barlow, N.D., 2000. Effects of dispersal on local population increase. Ecol. Lett. 3, 479-482.

Larsen, T.B., Pedgley, D.E., 1985. Indian migrant butterflies displaced to Arabia by monsoon storm 'Aurora' in August 1983. Ecol. Entomol. 10, 235-238.

Lofgren, C.S., 1986. The economic importance and control of imported fire ants in the United States. In: Vinson, S.B. (Ed.), Economic Impact and Control of Social Insects. Praeger Publishers, New York, pp. 227-256.

Mehdiabadi, N.J., Gilbert, L.E., 2002. Colony-level impacts of parasitoid flies on fire ants. Proc. R. Soc. Lond. B 269, 1695-1699.

Moriya, S., Shiga, M., Adachi, I., 2002. Classical biological control of the chestnut fall wasp in Japan. In: Proceedings of the 1st International Symposium on Biological Control of Arthropods, Radisson Hotel, Waikiki, Hawaii.

Morrison, L.W., 1999. Indirect effects of phorid fly parasitoids on the mechanisms of interspecific competition among ants. Oecologia 121, $113-122$.

Morrison, L.W., 2000. Mechanisms of Pseudacteon parasitoid (Diptera: Phoridae) effects on exploitative and interference competition in host Solenopsis ants (Hymenoptera: Formicidae). Ann. Ent. Soc. Am. 93, 841-849.

Morrison, L.W., Kawazoe, E.A., Guerra, R., Gilbert, L.E., 1999a. Phenology and dispersal in Pseudacteon flies (Diptera: Phoridae), parasitoids of Solenopsis fire ants (Hymenoptera: Formicidae). Ann. Ent. Soc. Am. 92, 198-207.

Morrison, L.W., Porter, S.D., Gilbert, L.E., 1999b. Sex ratio as a function of host size in Pseudacteon flies (Diptera: Phoridae), parasitoids of Solenopsis fire ants (Hymenoptera: Formicidae). Biol. J. Linn. Soc. 66, 257-267. 
Morrison, L.W., King, J.R., 2004. Host location behavior in a parasitoid of imported fire ants. J. Insect Behav. 17, 367-383.

Motulsky, H.J., Christopoulos, A., 2003. Fitting models to biological data using linear and nonlinear regression. A practical guide to curve fitting. GraphPad Software Inc., San Diego CA, www.graphpad.com.

Muirhead, J.R., Leung, B., van Overdijk, C., Kelly, D.W., Kandakurnar, K., Marchant, K.R., MacIsaac, H.J., 2006. Modeling local and longdistance dispersal of invasive emerald ash borer Agrilus planipennis (Coleoptera) in North America. Diversity Distrib. 12, 71-79.

Okubo, A., Levin, S.A., 2002. Diffusion and Ecological Problems: Modern Perspectives. Springer-Verlag, New York.

Orr, M.R., Selke, S.H., Benson, W.W., Gilbert, L.E., 1995. Flies suppress fire ants. Nature (Lond.) 373, 292-293.

Orr, M.R., Dahlsten, D.L., Benson, W.W., 2003. Ecological interactions among ants in the genus Linepithema, their phorid parasitoids, and ant competitors. Ecol. Entomol. 28, 203-210.

Pereira, R.M., Porter, S.D., 2006. Range expansion of the fire ant decapitating fly, Pseudacteon tricuspis, eight to nine years after releases in north Florida. Fla. Entomol. 89, 536-538.

Pesquero, M.A., Campiolo, S., Fowler, H.G., 1993. Phorids (Diptera: Phoridae) associated with mating swarms of Solenopsis saevissima (Hymenoptera: Formicidae). Fla. Entomol. 76, 179-181.

Porter, S.D., 1998. Biology and behavior of Pseudacteon decapitating flies (Diptera: Phoridae) that parasitize Solenopsis fire ants (Hymenoptera: Formicidae). Fla. Entomol. 81, 292-309.

Porter, S.D., Fowler, H.G., MacKay, W.P., 1992. Fire ant mound densities in the United States and Brazil (Hymenoptera: Formicidae). J. Econ. Entomol. 85, 1154-1161.

Porter, S.D., Pesquero, M.A., Campiolo, S., Fowler, H.G., 1995. Growth and development of Pseudacteon phorid fly maggots (Diptera: Phoridae) in the heads of Solenopsis fire ant workers (Hymenoptera: Formicidae). Environ. Ent. 24, 475-479.

Porter, S.D., Alonso, L.E., 1999. Host specificity of fire ant decapitating flies (Diptera: Phoridae) in laboratory oviposition tests. J. Econ. Entomol. 92, 110-114.

Porter, S.D., Nogueira de Sá, L.A., Flanders, K., Thompson, L., 1999. Field releases of the decapitating fly, Pseudacteon tricuspis [Abstract].
1999 Imported Fire Ant Conference Proceedings, Charleston, South Carolina, p. 102.

Porter, S.D., Pesquero, M.A., 2001. Illustrated key to Pseudacteon decapitating flies (Diptera: Phoridae) that attack Solenopsis saevissima complex fire ants in South America. Fla. Entomol. 84, 691-699.

Porter, S.D., Nogueire de Sá, L.A., Morrison, L.W., 2004. Establishment and dispersal of the fire ant decapitating fly Pseudacteon tricuspis in north Florida. Biol. Control 29, 179-188.

Richardson, C.H., Nemeth, D.J., 1991. Hurricane-borne African locusts (Schistocerca gregaria) on the Windward Islands. GeoJournal 23, 349-357.

Shigesada, N., Kawasaki, K., Takeda, Y., 1995. Modeling stratified diffusion in biological invasions. Am. Nat. 146, 229-251.

Skellam, J.G., 1951. Random dispersal in theoretical populations. Biometrika 38, 196-218.

Smith, J.R., Fuelberg, H.E., 2005. Warm season lightning distributions over the northern Gulf of Mexico coast and their relation to synopticscale and mesoscale environments. Weather Forecast. 20, 415-438.

Suarez, A.V., Holway, D.A., Case, T.J., 2001. Patterns of spread in biological invasions dominated by long-distance jump dispersal: insights from Argentine ants. Proc. Natl. Acad. Sci. USA 98, 1095-1100.

Taber, S.W., 2000. Fire Ants. Texas A\&M University Press, College Station, xvii $+308 \mathrm{pp}$.

Torres, J.A., 1988. Tropical cyclone effects on insect colonization and abundance in Puerto Rico. Acta Cient. 2, 40-44.

Tschinkel, W.R., 2006. The Fire Ants. Harvard University/Belknap Press, Cambridge, Massachusetts, 723 pp.

Turchin, P., 1998. Quantitative Analysis of Movement: Measuring and Modeling Population Redistribution in Animals and Plants, first ed. Sinauer Associates, Sunderland, 396 pp.

Vinson, S.B., 1997. Invasion of the red imported fire ant (Hymenoptera: Formididae): spread, biology, and impact. Am. Ent. 43, 23-39.

Williams, R.N., Panaia, J.R., Gallo, D., Whitcomb, W.H., 1973. Fire ants attacked by phorid flies. Fla. Entomol. 56, 259-262.

Yamamura, K., 2002. Dispersal distance of heterogeneous populations. Popul. Ecol. 44, 93-101. 